\title{
Performances of Three Cotton Varieties Cultivated under Economic Threshold Level Based Insecticide Sprayed and Non-Sprayed Conditions
}

\author{
H.M.S. Azad ${ }^{1}$, M.R. Amin ${ }^{2 *}$, D.A. Tithi ${ }^{2}$ and S.M.A. Hossain ${ }^{1}$ \\ ${ }^{1}$ Regional Cotton Research Station, Dinajpur 5200, Bangladesh \\ ${ }^{2}$ Department of Entomology, Hajee Mohammad Danesh Science and Technology University, Dinajpur 5200, \\ Bangladesh \\ *E-mail:ruhulhstu@yahoo.com
}

Received: 17.08.2011, Accepted: 12.11.2011

\begin{abstract}
Cotton growers of Bangladesh usually cultivate eleven varieties of cotton and abruptly use chemical insecticides for controlling pests. In this study we evaluated the performances of three extensively cultivated varieties (CB9, CB10 and SR05) under economic threshold level (ETL) based insecticide sprayed and non-sprayed conditions. Results showed that number of bolls per plant and yield of the varieties differ significantly and there was found significant difference between the experimental conditions. Our study showed that the variety SR05 produced significantly higher number of bolls $(40.5 \pm 6.6$ plant) and yield $(2498.3 \pm 18.9 \mathrm{~kg} / \mathrm{ha})$ compared to CB9 and CB10, whereas CB9 produced higher number of seed $(36.9 \pm 3.7 /$ boll $)$ and seed index $(83.4 \pm 0.9 \mathrm{~g} / 100 \mathrm{seed})$ under ETL based insecticide sprayed condition. The ginning out tern $(\mathrm{GOT} \%)$ and seed germination percentage of the studied varieties did not differ to a significant level. Overall fitness of the varieties indicated that SR05 possesses comparatively better performances for commercial production of cotton in Bangladesh.
\end{abstract}

Key words: Cotton, variety, yield, seed quality.

\section{Introduction}

Six hundred insects and spider species have been recorded in cotton fields (Hoffmann and Frodsham, 1993). The number of insect species that attack the crop as pest may be about 162 while significant damage is caused by 15 species (Dhawan, 2000). The most destructive pests of cotton in Bangladesh are jassid, aphid, white fly, thrips, spotted bollworm, american bollworm, pink bollworm and armyworm (Annual Research Report, 1999). These pests cause damage to cotton leaves, shoots, flowers, fruits and seeds by feeding and or transmitting diseases (Abou-Elhagag, 1998).
Cotton growers spray insecticides throughout the season to protect their crops, but indiscriminate uses of chemical insecticides create complications in the ecosystem and reduce the abundance of predators and insect pollinators. Morphological, physical or structural qualities of host plants interfere with insect feeding and reproduction behaviour (Goertzen and Small, 1993) and insects mostly feed and oviposit on high quality plants (Chen et al., 2004; Prudic et al., 2005). Researchers are working to establish economic threshold level (ETL) and also 
H.M.S. Azad, M.R. Amin, D.A. Tithi and S.M.A. Hossain / Our Nature (2011) 9: 21-25

improving varieties at which no action is needed to control pests. Therefore, the objective of this study was to quantify the yield and seed quality performances of three cotton varieties which are morphologically different and were grown under ETL based insecticide sprayed and non-sprayed conditions.

\section{Materials and methods Cultivation of crop}

The experiment was conducted in the Regional Cotton Research Station, Dinajpur, Bangladesh $\left(25^{\circ} 13^{\prime} \mathrm{N}, 88^{\circ} 23^{\prime} \mathrm{E}\right)$ during August, 2008 to March, 2009. The land was prepared at field condition by deep ploughing and harrowing followed by laddering. The field layout was done after final land preparation and the experiment was conducted in randomized complete block design. The plot size was $5.4 \times 5.0 \mathrm{~m}^{2}$ and the spacing between block to block and plot to plot was $1.5 \mathrm{~m}$ and $1.0 \mathrm{~m}$, respectively. Seeds of CB9, CB10 and SR05 were sown in rows with a spacing $45 \mathrm{~cm}$ from plant to plant and $90 \mathrm{~cm}$ from row to row. Intercultural operations such as mulching, weeding and irrigation etc were done whenever necessary. Crops were cultivated under ETL based insecticide sprayed and non-sprayed conditions. Application of fertilizers and ETL was estimated by the guideline of the Cotton Development Board of Bangladesh. Each cultivation condition was replicated three times for each variety. In the non-sprayed condition crops were exposed to natural infestation whereas in the ETL based insecticide sprayed condition Decis 2.5 EC and Asataf 75 SP were applied for controlling chewing and sucking pests, respectively.

\section{Observation of boll production}

Ten plants were selected randomly for each variety, fully opened bolls of these plants were picked up by hand and number of bolls produced in each plant was recorded.

\section{Observation of yield production}

Harvested cotton was weighed immediately to avoid hygroscopic effect. Amount of seed cotton of each variety obtained from same cultivation condition was converted to $\mathrm{kg} / \mathrm{ha}$. Seeds were exposed from the locks of the boll and number of seeds of each boll was recorded. Following ginning, separated fibers and seeds were weight separately, and the ginning out tern (the ratio of the weight of lint to that of seed cotton expressed as percentage) and seed index (weight in $\mathrm{g} / 100$ seeds) of each variety and cultivation conditions were determined.

Germination test was conducted using sand as substratum. The sand was sieved to discard particles bigger than $0.8 \mathrm{~mm}$ and smaller than $0.05 \mathrm{~mm}$ in diameter. Rectangular plastic boxes were used to put the sand. For every test new sand was used. Seed was placed on a uniform layer of moist sand and then covered to a depth of $10 \mathrm{~mm}$ with sand, which was left loose. 200 seeds were planted in each plastic tray and replicated three times. The plastic trays with seeds were incubated at room temperature and irrigated at every odd day. After 5 days, germination percentage was recorded. The normal seedlings and abnormal seedlings and nongerminated seeds were classified according to the prescribed rules given by International Seed Testing Association (ISTA) and germination rates were calculated using the following formula. 
H.M.S. Azad, M.R. Amin, D.A. Tithi and S.M.A. Hossain / Our Nature (2011) 9: 21-25

Germination $(\%)=$

Number of normal seeds germinated

Number of seeds tested

\section{Data analysis}

One way ANOVA following Duncan's Multiple Range Test (DMRT) and pair sample ' $T$ ' test were employed using SPSS (PASW Statistics 18) for analyzing the data.

\section{Results and discussion}

Boll production of CB9, CB10 and SR05 showed significant differences both in ETL based insecticide sprayed $\left(\mathrm{F}_{2,27}=3.72, \mathrm{p}=\right.$ $0.05)$ and no-sprayed $\left(\mathrm{F}_{2,27}=5.23, \mathrm{p}=0.05\right)$ conditions (Tab. 1). All the varieties produced significantly higher number of bolls under ETL based insecticide sprayed condition compared to non-sprayed condition (Tab. 1). This study also showed better performances of boll production under ETL based insecticide sprayed conditions compared to Amin et al. (2008) who applied insecticides to keep damage below economic injury level and found boll production 27.7, 24.7 and 29.0/plant of the varieties CB9, CB10 and SR05, respectively. Among the studied varieties, SR05 produced significantly higher number of bolls both ETL based insecticide sprayed (40.5 $\pm 6.6 /$ plant) and non-sprayed (12.6 \pm 3.1 /plant) conditions, because it is a moderately height and long lived variety having well ventilation (Amin et al., 2011). Yield of the varieties varied significantly both in ETL based insecticide sprayed $\left(\mathrm{F}_{2,6}\right.$ $=274.3, \mathrm{p}=0.001)$ and non-sprayed $\left(\mathrm{F}_{2,6}=\right.$ 233.9, $\mathrm{p}=0.001$ ) conditions (Tab. 2), and all the varieties showed significant differences between ETL based insecticide sprayed and non-sprayed conditions (Tab. 2). Results showed that yield obtained from ETL based insecticide sprayed conditions ranged from $2173.3 \pm 15.3$ to $2498.3 \pm 18.9$ $\mathrm{kg} / \mathrm{ha}$ and the variety SR05 produced significantly the highest yield. This variety also produced significantly higher yield $(792.3 \pm 8.7 \quad \mathrm{~kg} / \mathrm{ha}) \quad$ under non-sprayed condition. Obtained yield of CB9, CB10 and SR05 under ETL based insecticide sprayed condition in this study revealed better performances than Amin et al. (2008) who found 1650,1350 and $1600 \mathrm{~kg} / \mathrm{ha}$, respectively yield of these varieties.

Table 1. Number of boll production of three cotton varieties and their comparisons under ETL based insecticide sprayed and non-sprayed conditions

\begin{tabular}{lccccc}
\hline \multirow{2}{*}{ Variety } & \multicolumn{2}{c}{$\begin{array}{c}\text { Boll production } \\
\text { (mean } \pm \text { SD/plant) }\end{array}$} & \multicolumn{2}{c}{ t statistics } \\
\cline { 2 - 6 } & ETL based & Non-sprayed & t & df & P \\
\hline CB9 & $34.1 \pm 7.1 \mathrm{ab}$ & $11.5 \pm 2.9$ a & 8.7 & 9 & $<0.001$ \\
CB10 & $32.2 \pm 7.6 \mathrm{~b}$ & $8.2 \pm 3.5 \mathrm{~b}$ & 10.5 & 9 & $<0.001$ \\
SR05 & $40.5 \pm 6.6 \mathrm{a}$ & $12.6 \pm 3.1 \mathrm{a}$ & 15.7 & 9 & $<0.001$ \\
\hline
\end{tabular}

$\mathrm{N}=10$ plants for each variety and treatment. Means within a column followed by same letter(s) are not significantly different by DMRT $(\mathrm{p} \leq 0.05)$

Table 2. Yield (seed cotton) of three cotton varieties and their comparisons under ETL based insecticide sprayed and non-sprayed conditions

\begin{tabular}{lccccc}
\hline Variety & \multicolumn{2}{c}{ Yield (mean \pm SD Kg/ha) } & \multicolumn{4}{c}{ t statistics } \\
\cline { 2 - 7 } & ETL based & Non-sprayed & t & df & P \\
\hline CB9 & $2248.3 \pm 18.9 \mathrm{~b}$ & $749.3 \pm 9.0 \mathrm{~b}$ & 120.7 & 2 & $<0.001$ \\
CB10 & $2173.3 \pm 15.3 \mathrm{c}$ & $618.3 \pm 12.6 \mathrm{c}$ & 123.6 & 2 & $<0.001$ \\
SR05 & $2498.3 \pm 18.9$ a & $792.3 \pm 8.7$ a & 125.6 & 2 & $<0.001$ \\
\hline
\end{tabular}

The studied cotton varieties showed significant differences on production of seeds per boll under ETL based insecticide sprayed $\left(\mathrm{F}_{2,27}=3.2, \mathrm{p}=0.05\right)$ and nosprayed $\left(\mathrm{F}_{2,27}=4.2, \mathrm{p}=0.05\right)$ conditions (Tab. 3). But comparisons between ETL based insecticide sprayed and no-sprayed 
conditions for each variety were statistically insignificant (Tab. 3). Among the varieties CB9 produced significantly the highest number of seeds/boll both under ETL based insecticide sprayed $(36.9 \pm 3.7)$ and nonsprayed conditions $(34.2 \pm 2.2)$. This may be the reason that boll size of $\mathrm{CB} 9$ is comparatively bigger (Amin et al., 2011)

Table 3. Number of seed production of three cotton varieties and their comparisons under ETL based insecticide sprayed and non-sprayed conditions

\begin{tabular}{lccccc}
\hline \multirow{2}{*}{ Variety } & \multicolumn{3}{c}{$\begin{array}{c}\text { Seed production } \\
\text { (mean } \pm \text { SD number/boll) }\end{array}$} & \multicolumn{2}{c}{ t statistics } \\
\cline { 2 - 6 } & ETL based & Non-sprayed & t & df & P \\
\hline CB9 & $36.9 \pm 3.7 \mathrm{a}$ & $34.2 \pm 2.2 \mathrm{a}$ & 2.1 & 9 & 0.06 \\
$\mathrm{CB} 10$ & $32.2 \pm 4.1 \mathrm{~b}$ & $30.1 \pm 3.3 \mathrm{~b}$ & 1.9 & 9 & 0.09 \\
$\mathrm{SR} 05$ & $35.5 \pm 4.7 \mathrm{ab}$ & $32.1 \pm 3.8 \mathrm{ab}$ & 1.6 & 9 & 0.12 \\
\hline
\end{tabular}

Means within a column followed by same letter(s) are not significantly different by DMRT $(\mathrm{p} \leq 0.05)$

Table 4. Ginning out tern (GOT\%) of three cotton varieties and their comparisons under ETL based insecticide sprayed and non-sprayed conditions

\begin{tabular}{lccccc}
\hline \multirow{2}{*}{ Variety } & \multicolumn{2}{c}{ GOT\% (mean \pm SD) } & \multicolumn{3}{c}{ t statistics } \\
\cline { 2 - 6 } & ETL based & Non-sprayed & t & df & P \\
\hline CB9 & $37.4 \pm 0.7 \mathrm{a}$ & $37.0 \pm 0.4 \mathrm{a}$ & 0.6 & 2 & 0.59 \\
CB10 & $37.5 \pm 0.7 \mathrm{a}$ & $37.3 \pm 0.9 \mathrm{a}$ & 0.2 & 2 & 0.85 \\
SR05 & $36.6 \pm 0.5 \mathrm{a}$ & $36.2 \pm 0.5 \mathrm{a}$ & 4.0 & 2 & 0.06 \\
\hline
\end{tabular}

Means within a column followed by same letter(s) are not significantly different by DMRT $(\mathrm{p} \leq 0.05)$

Table 5. Seed index (weight of 100 seeds) of three cotton varieties and their comparisons under ETL based insecticide sprayed and non-sprayed conditions

\begin{tabular}{lccccc}
\hline \multirow{2}{*}{ Variety } & \multicolumn{2}{c}{ Seed index (mean \pm SD g) } & \multicolumn{4}{c}{ t statistics } \\
\cline { 2 - 6 } & ETL based & Non-sprayed & t & df & P \\
\hline CB9 & $83.4 \pm 0.9 \mathrm{a}$ & $83.0 \pm 0.7 \mathrm{a}$ & 0.4 & 2 & 0.75 \\
CB10 & $75.2 \pm 1.0 \mathrm{c}$ & $75.1 \pm 0.6 \mathrm{c}$ & 0.5 & 2 & 0.67 \\
SR05 & $78.1 \pm 0.5 \mathrm{~b}$ & $77.9 \pm 0.7 \mathrm{~b}$ & 0.5 & 2 & 0.68 \\
\hline
\end{tabular}

Means within a column followed by same letter(s) are not significantly different by DMRT $(\mathrm{p} \leq 0.05)$

and thus produced higher number of seeds. Ginning out tern (GOT\%) of CB9, CB10 and SR05 varied from $36.6 \pm 0.5$ to $37.5 \pm 0.7$ (Tab. 4) and these results were found under
ETL based insecticide sprayed conditions and the results did not vary significantly $\left(\mathrm{F}_{2,6}=1.86, \mathrm{p}=0.24\right)$. GOT\% of these varieties under non-sprayed conditions ranged from $36.2 \pm 0.5$ to $37.3 \pm 0.9$ (Tab. 4) and these results also did not show significant difference $\left(\mathrm{F}_{2,6}=2.45, \mathrm{p}=0.16\right)$, and comparisons of the varieties grown under ETL based insecticide sprayed and non-sprayed conditions were statistically insignificant (Tab. 4). There were significant differences among the seed index of the varieties both in ETL based insecticide sprayed $\left(\mathrm{F}_{2,6}=79.8, \mathrm{p}=0.001\right)$ and non-sprayed $\left(\mathrm{F}_{2,6}=107.6, \mathrm{p}=0.001\right)$ conditions. But comparisons of the seed index of the varieties were statistically similar between the conditions (Tab. 5). Germination percentage of CB9, CB10 and SR05 were found statistically similar both in ETL based insecticide sprayed $\left(\mathrm{F}_{2,6}=\right.$ $0.06, \mathrm{p}=0.95)$ and non-sprayed $\left(\mathrm{F}_{2,6}=0.03\right.$, $\mathrm{p}=0.98)$ conditions, and there was no significant difference between the conditions of the experiment (Tab. 6).

Table 6. Germination performance of three cotton varieties and their comparisons under ETL based insecticide sprayed and non-sprayed conditions

\begin{tabular}{lccccc}
\hline \multirow{2}{*}{ Variety } & \multicolumn{2}{c}{ Germination } & (mean \pm SD\%) & \multicolumn{3}{c}{ t statistics } \\
\cline { 2 - 6 } & ETL based & Non-sprayed & t & df & P \\
\hline CB9 & $87.3 \pm 2.9 \mathrm{a}$ & $81.3 \pm 6.1 \mathrm{a}$ & 1.2 & 2 & 0.36 \\
$\mathrm{CB} 10$ & $88.3 \pm 4.0 \mathrm{a}$ & $82.3 \pm 6.0 \mathrm{a}$ & 1.7 & 2 & 0.24 \\
SR05 & $87.7 \pm 4.0 \mathrm{a}$ & $81.7 \pm 4.7 \mathrm{a}$ & 1.2 & 2 & 0.36 \\
\hline Means within a column followed by same letter(s) are \\
not significant
\end{tabular}

The results of this study indicated that all the varieties produced significantly higher number of bolls and yield under ETL based insecticide sprayed condition compared to non-sprayed condition. But seed production, ginning out tern, seed index and germination percentage were 
H.M.S. Azad, M.R. Amin, D.A. Tithi and S.M.A. Hossain / Our Nature (2011) 9: 21-25

statistically similar under those conditions. Indiscriminate use of chemical insecticides in the cotton field adversely affect the beneficial insect fauna (Khattak et al., 2004) whereas threshold sprayed avoid unnecessary burden of the environment and justifies the use of control measures and resulted more yield and profit (Ali and Karim, 1990). SR05 is a serrated leaf variety with well ventilated, potential and prudent enough to overcome insect attack. It is surprisingly true that the yield contributing characters such as plant height, boll size, boll weight and number of bolls are enthusiastic in the varieties CB9 and SR05. So, these varieties possessed comparatively better performances for commercial cultivation of cotton in Bangladesh.

\section{References}

Abou-Elhagag, G.H. 1998. Seasonal abundance of certain cotton pest and their associated natural enemies in Southern Egypt. Assiat. J. Agril. Sci. 29: $253-267$.

Ali, M.I. and M.A. Karim 1990. Threshold spray of insecticides: its advantages on conservation of arthropod predators and parasites in cotton ecosystem in Bangladesh. Bangladesh J. Entomol. 18: $17-22$.
Amin, M.R., D.A. Tithi and Y.J. Kwon 2011 Characteristics of three cotton varieties and their impact on feeding and growth of cotton armyworm. Ent. Res. 41: 151-156.

Amin, M.R., M.A. Ahad, M.H. Hossain, S.M.A. Hossain and D.A. Tithi 2008. Characteristics of some cotton varieties in relation to seasonal abundance of pests, predators and their impact on yield and quality. J. Agrofor. Environ. 2: 67-70.

Annual Research Report 1999. Cotton Development Board, Khamarbari, Farmgate, Dhaka, Bangladesh.

Chen, Y.Z., I. Lin, C.W. Wang, C.C. Yeh and S.Y. Hwang 2004. Response of two Pieris (Lepidoptera: Pieridae) species to fertilization of a host plant. Zool. Studies. 43: 778-786.

Dhawan, A.K. 2000. Major insect pests of cotton and their management. Aditya Books Pvt Ltd, New Delhi. pp. 165-225.

Goertzen, L.R. and E. Small 1993. The defensive role of trichomes in black meduck Medicago lupulina F. Pl. Syst. Evol. 184: 101-111.

Hoffmann, M.P. and A.C. Frodsahm 1993. Natural enemies of vegatable insect pests. Cooperative extension, Cornell Univ., Ithaca, NY. 63p.

Khattak, K.K., S.D. Khan, L. Khan and G.S. Shah 2004. Efficacy of various insecticides on the damage and incidence of cotton boll worms and beneficial fauna. Pak. Entomol. 26: 19-23.

Prudic, K.L., J.C. Oliver and M.D. Bowers 2005. Soil nutrient effects on oviposition preference, larval performance and chemical defense of a specialist insect herbivore. Oecologia. 143: 578-587. 